\title{
Investigation of Empirical Wave Propagation Models in Precision Agriculture
}

\author{
N. Sabri ${ }^{1 *}$, Mohammed S. S ${ }^{2}$, Sarah Fouad ${ }^{3}$, Syed A. A ${ }^{1}$, Fahad Taha AL-Dhief ${ }^{5}$, Auda Raheemah $^{4}$ \\ ${ }^{1}$ Computer and Communication Engineering School, University Malaysia Perlis, Malaysia \\ ${ }^{2,3}$ Laser and Optoelectronics Engineering Dept., ${ }^{1 *}$ Computer Eng. Dept., AlNahrain University, Iraq \\ ${ }^{3}$ Microelectronic Engineering School, University Malaysia Perlis, Malaysia \\ ${ }^{5}$ Center of Software Technology and Management, University Kebangsaan Malaysia, Malaysia \\ ${ }^{4}$ Computer Engineering Dept., College of Engineering, ALMuthana University, Iraq
}

\begin{abstract}
Wireless Sensor Networks have highly proved its contribution in precision agriculture. Communication channel modelling investigation is a highly demanded to achieve a successful communication system where a good wave propagation model is crucially needed. Precision agriculture degrades the traveling waves in various forms in addition to the effects of the large-scale path losses models. This paper reviews the most known theoretical large-scale path losses models such as free space (FSPL) and Plane earth (PE) models as well as the vegetation models represented by Weissberger, ITU-R, FITU-R and COS235 models. Indeed, this work illustrates the effects of many factors on the total path losses such as separation distance between transceivers, antenna heights and the depth of vegetation that presence in the path propagation. In conclusion, the total path loss is computed based on large-scale path losses and the vegetation losses in protected vegetation environment.
\end{abstract}

\section{Introduction}

Wireless sensor networks (WSNs) technologies have dominate a various crucial applications starting from home, precision agriculture, industrial and chemical to space applications. All are aiming monitor and tracking and emergency relief. WSNs mostly, are composed of spatial distributed routers and end nodes which can be in large or small number where network end nodes are assumed to function autonomously in a very cruel situations [1]. Precision agriculture offers the ways for the agricultural practices to be monitored, evaluated and controlled. It covers abroad diversity of agricultural tendencies from diurnal herd management over gardening to yields' cultivation and production. WSNs offer a means for all time monitoring of entity crop and its provisions that will assist farmers to potentially identify a multiplicity of irrigation, climate automation, fertilizers, ventilation, and other necessities which offer the crop with perfect environment and conditions for growing [2]. While end nodes of WSN are spatially located with low elevation from earth surface and thus absences of main ray between network nodes transceivers, even though those nodes have spatially short distance distribution. Hence, WSNs propagation signals may obstacle by dense foliage, fence, building, trees [3]. Thus, the current propagation models of wireless communication might not be accurate defining the propagation channel behaviour of WSN. Therefore, for WSNs a precise model of propagation must be adopted that well describe the signal and its environment [3]. Simulation tools will highly assist with characterization and modelling of WSN propagation channel which is consider as a primarily indication of successful implementation of WSNs [1].

This research adopted four vegetation models of well-known empirical based modelling. Those vegetation models, COST235, ITU- Recommendation (ITU-R), Weissberger and FITU-R, are simulated to find the vegetation losses with WSNs communication nodes.

\section{Empirical RF models in simulation environment}

WSNs propagation channel assessment is predicted with respect to propagation models within the aids of simulation tools. However, most of the well-known simulators adopt free of sight propagation channel, no obstacles, thus line of sight environment is simulated (LOS), but the results are consider very optimistic and inadequately reflect the empirical real time scenario. Like as, part of plantation area will produce addition attenuation factor over propagation signal and thus affects channel performance of the WSNs nodes. Hence, the most reliable describing of channel propagation must

\footnotetext{
*Corresponding author: naseersabri@yahoo.com
} 
combine the vegetation losses with other signal attenuation factors like reflection and transceivers distance. The foliage imposed affects in addition to multiple instants of reflected signal from the ground and perchance arbour canopy will formulate the total propagation path loss of small distance near ground agricultural environment, as per recommended in [4][5]. In wireless communications, the average received energy of transmitted wave is computed based on signal path loss models whereas the received power are inversely related to transceivers distance. Such models are characteristically shaped according to environmental characteristics.

Propagation models are mainly categorized as a two well-known channel modelling approaches, theoretical and empirical propagation models [6]. Although theoretical-model approach based on the facts of the physical laws of the communication path such as electrical properties of ground, empirical propagation attenuation models are depend on real radio frequency measurands of communication channels. The simplicity of implementation and its ability to cover all environment-related factors that affect the propagation of the radio wave throughout actual measurements [6] introduces empirical path losses models over theoretical path loss models. The accurate wave propagation model for wireless sensor network are expected to support in achieving suitable valuation with improving of wireless sensors networks performance all over the deployment planning process, minimizing the power consumption of network end nodes and to enhance the localization and target sensing tasks [7].

\section{Large Scale Propagation Models}

These models are used to estimate the mean received signal strength (RSS) of the propagate wave between transmitter and receiver since they characterize the RSS over large separation distance between transceivers. Mainly large scale models are categorized into well-known two models; free space path loss model (FSPL) and plane earth model (PE) were used in most researches [8].

\subsection{Obstacle clear Path Loss propagation model}

Obstacle clear propagation model is well known as free space path loss (FSPL) model valuated by the loss in the received signal strength (RSS) with respect to transmission signal energy, when there is obstacle free wave traveling path between the transceivers [8].

$P L_{F S P L}(d B)=-27.56+20 \log (d)+20 \log (f)$

where $d$ is the distance in meter, and $f$ is the signal frequency in $\mathrm{MHz}$;

\subsection{Plane Earth Path loss (PE) model}

The $P E$ model computes the path loss of a traveling wave based on the antenna heights of transmitter and receiver that may present the plane earth reflection of the transmitted signal into the receiver antenna [9]; Path loss can be calculated by equation 2 .

$P L_{P E}(d B)=40 \log (d)-20 \log \left(h_{t}\right)-20 \log \left(h_{r}\right)$

The separation distance $(d)$ in meter, and the transmitter and receiver antennas height represented by $\left(h_{t}\right)$ and $(h r)$ respectively. The large scale broadcast models is not completely appropriate where the detraction, reflection, and scattering properly disturb the communication channel and affects widely of the received signal as within practical tasks. However, $P E$ formula in (2) can be adopted to provide early assessment of what to be predicted [9].

\section{Vegetation models}

WSN in agricultural application such as greenhouse where the nodes are deployed near ground and there vegetation between these nodes caused many effects on the RSS. Path losses can be modeled experimentally based on the equation (3) [10], where the depth of vegetation $\left(d_{f}\right)$ and frequency are the parameter of $P L_{v e g}$, $A, B$, and $C$ are constant empirically determined.

$$
P L_{v e g}(d B)=A \cdot f^{B} \cdot d_{f}^{C}
$$

\subsection{Weissberger model [6]}

It is applicable in situations where propagation is occurred through the grove of trees:

$$
P L_{\text {weiss }}(d B)= \begin{cases}1.33 \times f^{0.284} \times d_{f}^{0.588} & 14 m<d_{f} \leq 400 m \\ 0.45 \times f^{0.284} \times d_{f} & 0 m \leq d_{f}<14 m\end{cases}
$$

where $P L_{\text {Weiss }}$ is the vegetation loss in $\mathrm{dB}, f$ is the frequency in $\mathrm{GHz}$, and $d_{f}$ is the depth of the trees in meter.

\subsection{ITU-R model [11]}

The Weissberger vegetation model shows fairly matching with ITU-R model. The ITU-R model is computed based on equation (5), where the frequency used $(f)$ in $\mathrm{MHz}$ and the transceivers apart distance $\left(d_{f}\right)$ in meters. Equation (5) shows ITU-R vegetation loss;

$$
P L_{I T U-R}(d B)=0.2 \times f^{0.3} \times d_{f}^{0.6}
$$

\subsection{Fitted ITU-R (FITU-R) Model [12]}

carried out using measurement data at 11.2 and $20 \mathrm{GHz}$ $(\mathrm{d}<120 \mathrm{~m})$.

$$
P L_{F I T U-R}(d B)= \begin{cases}0.37 \times f^{0.18} \times d_{f}^{0.59} & \text { out of leaf } \\ 0.39 \times f^{0.39} \times d_{f}^{0.25} & \text { in leaf }\end{cases}
$$


Where the vegetation loss of fitted ITU-R (PLFTITU-R) in $\mathrm{dB}$ and the propagation frequency $(f)$ in $\mathrm{MHz}$ while the vegetation depth of trees $\left(d_{f}\right)$ in meters.

\subsection{COST 235 vegetation model}

This vegetation model computes the path loss in $(d B)$ with propagation wave frequency in the range of 9.6 $\mathrm{GHz}$ to $57.6 \mathrm{GHz}$ throughout a short vegetation distance $\left(d_{f}\right)$ less than $200 \mathrm{~m}$ of fluting of trees [13]:

$$
P L_{\text {COST } 235}(d B)= \begin{cases}26.6 \times f^{-0.2} \times d_{f}^{0.5} & \text { out of leaf } \\ 15.6 \times f^{-0.009} \times d_{f}^{0.26} & \text { in leaf }\end{cases}
$$

\section{Path Losses $\left(P_{\text {Ltot }}\right)$ in vegetation environment}

When WSN nodes deployed in vegetation environments, the receive power effects by vegetation that caused additional losses, then the total path losses can be formulated by combines the losses due PE model with the vegetation losses $P L_{\text {veg }}$ that prediction by different vegetation models [3][14].

$$
P L_{\text {tot }}=P L_{P E}+P E_{v e g}
$$

Where $P L_{\text {tot }}$ is the total path losses, $P L_{P E}$ is the path losses in free-space and $P L_{\text {veg }}$ the path losses due to vegetation.

\section{Simulation Setup}

The simulation assumes a greenhouse of $100 \mathrm{~m} \times 100 \mathrm{~m}$ area where wireless sensor nodes are deterministically deployment over this area with $10 \mathrm{~m}$ distance between each adjacent nodes. The total number of nodes are 100 . The terrain of greenhouse assumes to be flat. The setup of greenhouse wireless sensor network nodes is listed in Table .1.

Table 1. Parameter setting for simulation Setup

\begin{tabular}{|l|l|}
\hline Topology & Star topology \\
\hline Transmit power & $0 \mathrm{dBm}$ \\
\hline Frequency operation & $2.245 \mathrm{GHz}$ \\
\hline Data rate & $250 \mathrm{kbps}$ \\
\hline receiver sensitivity & $-95 \mathrm{dBm}$ \\
\hline Antenna Type & Omni-directional \\
\hline Pattern of deployment & Square grid \\
\hline
\end{tabular}

\section{Results and discussions}

WSN nodes when deployment in agricultural environments, propagation wave facing obstruction by the vegetation that existence in these environments, this obstruction caused excess losses added to losses that predicted by large scale propagation models alone. The excess losses must be determined by the abovementioned vegetation models. Investigation of large scale path loss models based on antenna heights and separation distance is depicted in Figure.1. The effects of antenna heights on the path losses that predicted by large scale propagation models (FSPL and PE) when antenna are located at the same level (line of sight). The simulation results explain that the $\mathrm{PL}_{\text {tot }}$ are decreased with increasing the heights of antenna while it increases with increasing the separation distance between transceivers.

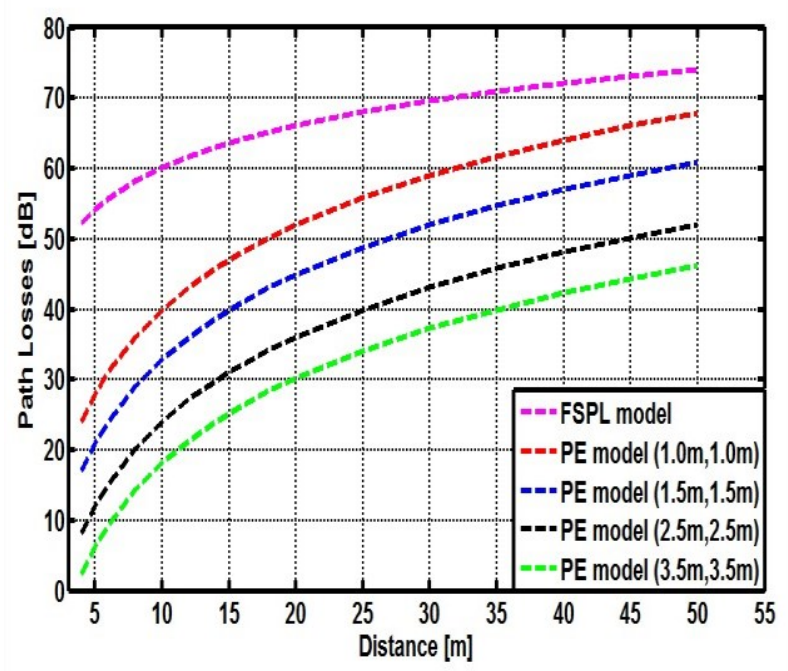

Fig. 1. Path loss versus separation distance at (LOS situation)

Figure. 2 show the relation between $P L_{\text {tot }}$ that predicted by combined of $P E$ model and vegetation models with vegetation depths at different heights of antenna. For comparing between $P L_{\text {tot }}$ that predicted by large scale propagation models (FSPL and $P E$ ) alone with $P L_{t o t}$ predicated by combined large scale model with vegetation models, explain that, the large scale models (FSPL and $P E$ ) are very optimistic models and don't take into account the effects of vegetation that existence in the path of propagation. Hence, predication by $P L_{t o t}$ at such environments required more accurate model.

The total path losses $\left(P L_{t o t}\right)$ simulated values demonstrate that $P L_{\text {tot }}$ computed based vegetation model of equal heights of antenna of line of sight environment is less than $P L_{t o t}$ based different antenna heights. Although that, like this formation is demanded in practical field. The simulation results show that the $P L_{t o t}$ that calculates by vegetation models at same heights of antenna (LOS) found be less than $P L_{\text {tot }}$ that calculates at different antenna heights but this configuration is required in real field. Our simulation assumes the receive antenna are hanged in roof of greenhouse at height $3.5 \mathrm{~m}$. In the simulated field, the relation of $P L_{t o t}$ and the vegetation depth is presented in Figure 3. The antennas heights are varied with a range of $0.5 \mathrm{~m}$ to $2.5 \mathrm{~m}$ within incremental step of $0.5 \mathrm{~m}$. 


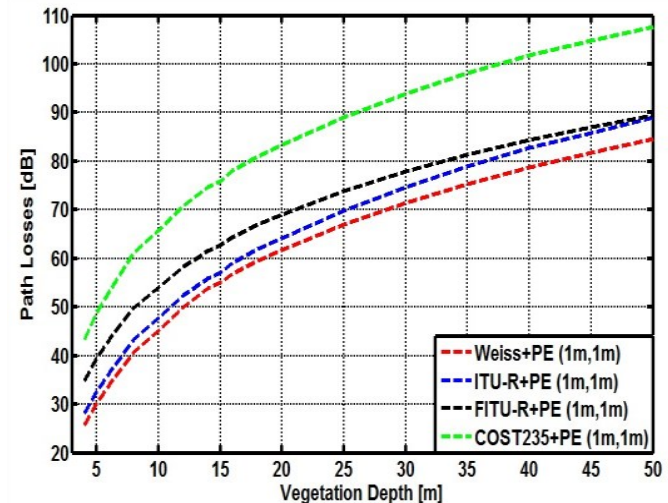

(a) $\mathrm{Hr}=1 \mathrm{~m}, \mathrm{Ht}=1 \mathrm{~m}$

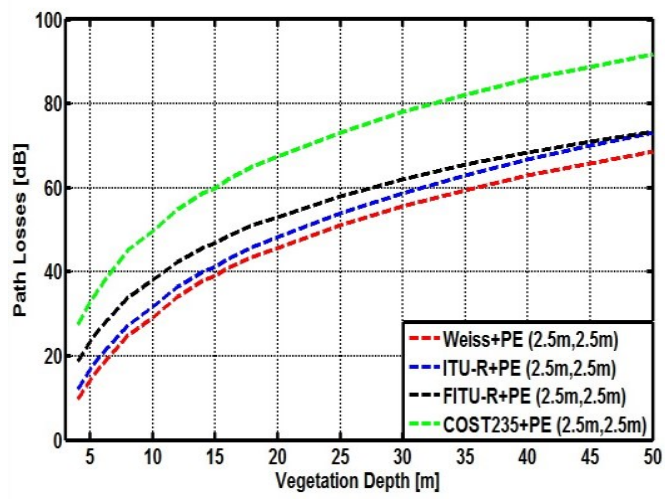

(c) $\mathrm{Hr}=2.5 \mathrm{~m}, \mathrm{Ht}=2.5 \mathrm{~m}$

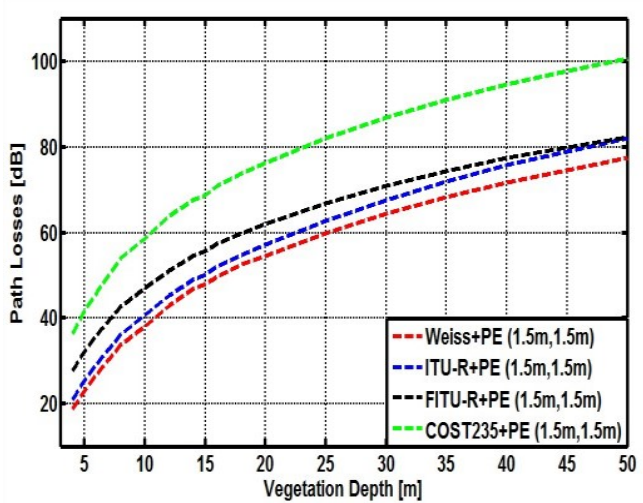

(b) $\mathrm{Hr}=1.5 \mathrm{~m}, \mathrm{Ht}=1.5 \mathrm{~m}$

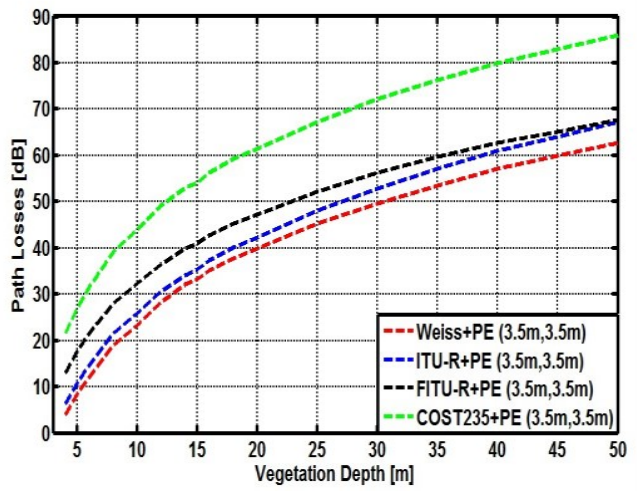

(d) $\mathrm{Hr}=3.5 \mathrm{~m}, \mathrm{Ht}=3.5 \mathrm{~m}$

Fig. 2. Total path loss versus separation distance at (LOS situation)

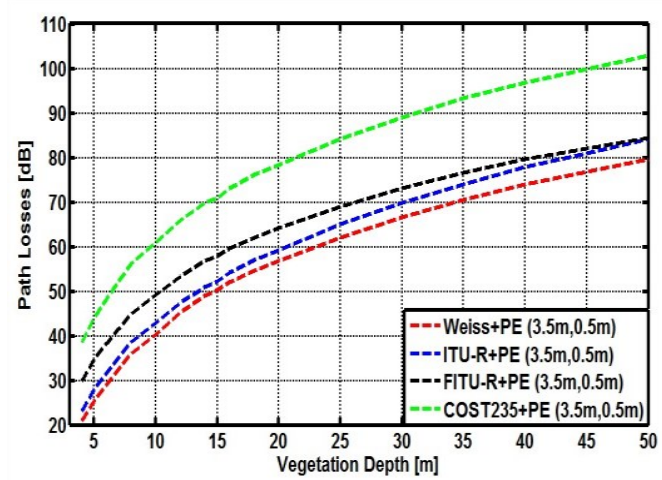

(a): $\mathrm{Hr}=3.5 \mathrm{~m}, \mathrm{Ht}=0.5 \mathrm{~m}$

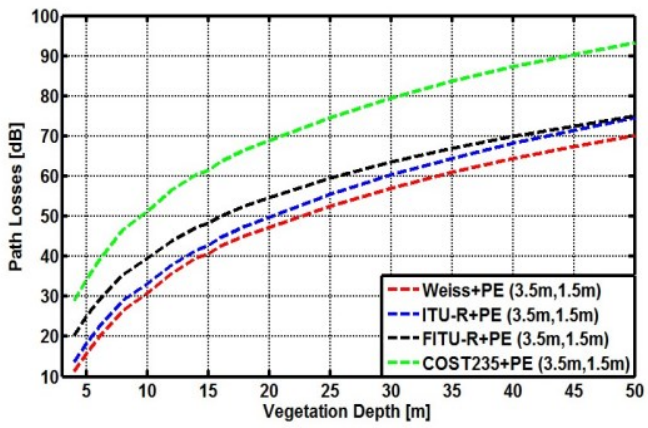

(c): $\mathrm{Hr}=3.5 \mathrm{~m}, \mathrm{Ht}=1.5 \mathrm{~m}$

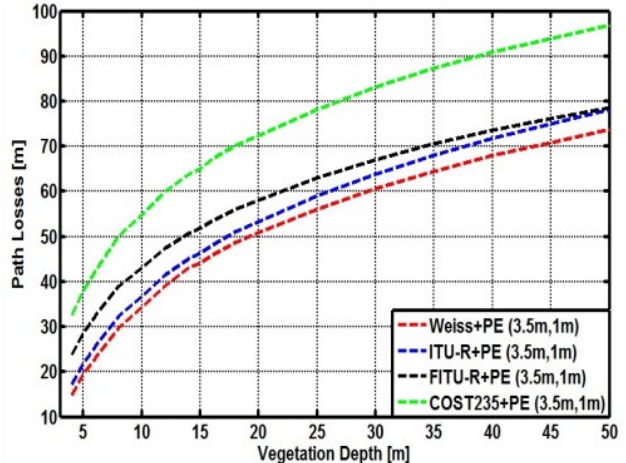

(b): $\mathrm{Hr}=3.5 \mathrm{~m}, \mathrm{Ht}=1 \mathrm{~m}$

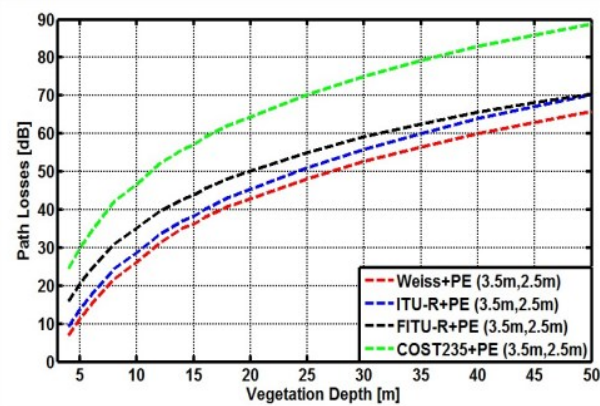

(d): $\mathrm{Hr}=3.5 \mathrm{~m}, \mathrm{Ht}=2.5 \mathrm{~m}$

Fig. 3. Total path loss versus separation distance at different antenna heights 
The results show that the models have the best $P L_{t o t}$ as the location of antenna is raised from the ground. For example the models have the following $P L_{\text {tot }}$ (62.14, 65.01, 69.09 and 84.29)dB for (Weiss+PE, ITU-R+PE, FITU-R+PE and COST235+PE) respectively at $\left(d_{f}=25 \mathrm{~m}\right)$ and antenna heights are $(3.5 \mathrm{~m}, 0.5 \mathrm{~m})$ of Figure 3a, whereas, the same models have the following $P L_{\text {tot }}$ $(52.6,55.46,59.55$ and 74.74$) \mathrm{dB}$ for (Weiss+PE, ITU$\mathrm{R}+\mathrm{PE}$, FITU-R+PE and COST235+PE) respectively at same $d_{f}$ but when the antenna heights are $(3.5 \mathrm{~m}, 1.5)$ of Figure 3c.

\section{Conclusions}

WSN nodes when deployment in agricultural environments, propagation wave facing obstruction by the vegetation that existence in these environments. An optimistic results was shown for $P L_{t o t}$, in the simulation, based large scale propagation models and thus these models produce $P L_{t o t}$ values far from realistic models. These results do not reflected the effects of objects that existence in real environments. Therefore, cannot depends on large scale propagation models to predicted by $P L_{t o t}$ in such environments, an accurate models must be used for reliable communication. The simulation results show the relation between the antenna heights and $P L_{\text {tot }}$, losses will be decrease with increasing the heights of antennas. Also the effect of vegetation existence in the path of propagation was investigated, the results show the relation between $P L_{t o t}$ and the depth of vegetation where $P L_{t o t}$ will be increase with increasing the depth of vegetation.

\section{References}

1. Sabri, N., Aljunid, S. A., Salim, M. S., Fouad, S., \& Kamaruddin, R. (2015). Wireless Sensor Network Wave Propagation in Vegetation. In Recent Trends in Physics of Material Science and Technology (pp. 283-298). Springer Singapore

2. Serodio, C., Cunha, J. B., Morais, R., Couto, C., \& Monteiro, J. (2001). A networked platform for agricultural management systems. Computers and electronics in agriculture, 31(1), 75-90.

3. Auda Raheemah, Naseer Sabri, Phaklen Ehkan, R. Badlishah and M. S. Salim (2015). Influences of Parts of Tree on Propagation Path Losses for WSN Deployment In Greenhouse Environments. Journal of Theoretical and Applied Information Technology December 2015. Vol. 82. No.2
4. Meng, Y. S., Lee, Y. H., \& Ng, B. C. (2010). Path loss modeling for near-ground vhf radio-wave propagation through forests with tree-canopy reflection effect. Progress In Electromagnetics Research M, 12, 131-141.

5. Sabri N, Aljunid SA, Ahmad RB, Malek MF, Yahya A, Kamaruddin R, Salim MS (2012). Performance Evaluation of Wireless Sensor Network Channel in Agricultural Application. American Journal of Applied Sciences. 9 (1), pp: 141-151, 2012.

6. Rappaport, Theodore S. Wireless communications: principles and practice. 2nd Eddition. New Jersey: Prentice Hall PTR, 2002.

7. AlSayyari, A., Kostanic, I., Otero, C., Almeer, M., \& Rukieh, K. (2014, March). An empirical path loss model for wireless sensor network deployment in a sand terrain environment. In Internet of Things (WF-IoT), 2014 IEEE World Forum on (pp. 218223). IEEE.

8. Zhou, G., He, T., Krishnamurthy, S., \& Stankovic, J. A. (2004, June). Impact of radio irregularity on wireless sensor networks. In Proceedings of the 2nd international conference on Mobile systems, applications, and services (pp. 125-138). ACM.

9. Kirubanand, V. B., \& Palaniammal, S. (2011). Study of performance analysis in wired and wireless network. American Journal of Applied Sciences, 8(8), 826.

10. Sklar, Bernard. Digital Communications: Fundamentals and Applications. 2nd Eddition. New Jersey: Prentice Hall PTR, 2001.

11. Hebel, M. A., Tate, R. F., \& Watson, D. G. (2007). Results of wireless sensor network transceiver testing for agricultural applications. In 2007 ASAE Annual Meeting (p. 1). American Society of Agricultural and Biological Engineers.

12. Thelen, J., Goense, D., \& Langendoen, K. (2005, April). Radio wave propagation in potato fields. In 1st Workshop on Wireless Network Measurements (Vol. 2, pp. 331-338).

13. Janek, J. F., \& Evans, J. J. (2010). Predicting ground effects of omnidirectional antennas in wireless sensor networks. Wireless Sensor Network, 2(12), 879.

14. Auda Raheemah, Naseer Sabri, M.S. Salim, Phaklen Ehkan, R. Badlishah Ahmad (2016). New empirical path loss model for wireless sensor networks in mango greenhouses. Computers and Electronics in Agriculture 127 (2016) 553-560. 